\title{
Application of the Cell Perturbation Method to Large-Eddy Simulations of a Real Urban Area
}

\author{
GWANG-JIN LEE \\ Department of Mathematics, Yonsei University, Seoul, South Korea \\ DOMINGO MUÑOZ-ESPARZA \\ National Center for Atmospheric Research, Boulder, Colorado \\ CHAEYEON Yi \\ Department of Environmental Science, Hankuk University of Foreign Studies, Gyeonggi-do, South Korea \\ Hi JUN CHOE \\ Department of Mathematics, Yonsei University, Seoul, South Korea
}

(Manuscript received 12 July 2018, in final form 28 February 2019)

\begin{abstract}
With the continuous increase in computing capabilities, large-eddy simulation (LES) has recently gained popularity in applications related to flow, turbulence, and dispersion in the urban atmospheric boundary layer (ABL). Herein, we perform high-resolution building-scale LES over the Seoul, South Korea, city area to investigate the impact of inflow turbulence on the resulting turbulent flow field in the urban ABL. To that end, LES using the cell perturbation method for inflow turbulence generation is compared to a case where no turbulence fluctuations in the incoming ABL are present (unperturbed case). Validation of the model results using wind speed and wind direction observations at $3 \mathrm{~m}$ above ground level reveals minimal differences irrespective of the presence of incoming ABL turbulence. This is due to the high density of building structures present at the surface level that create shear instabilities in the flow field and therefore induce local turbulence production. In the unperturbed case, turbulent fluctuations are found to slowly propagate in the vertical direction with increasing fetch from the inflow boundaries, creating an internal boundary layer that separates the turbulent region near the building structures and the nonturbulent flow aloft that occupies the rest of the ABL. Analysis of turbulence quantities including energy spectra, velocity correlations, and passive scalar fluxes reveals significant underpredictions that rapidly grow with increasing height within the ABL. These results demonstrate the need for realistic inflow turbulence in building-resolving LES modeling to ensure proper interactions within the ABL.
\end{abstract}

\section{Introduction}

Recently, large-eddy simulation (LES) models have been used to simulate building-scale wind patterns, pollutant dispersion, and air ventilation effects subject to the presence of the atmospheric boundary layer (ABL) (e.g., Smolarkiewicz et al. 2007; Lundquist and Chan 2007; Letzel et al. 2008; Lundquist et al. 2012; Chen et al. 2015; Park et al. 2015; Gronemeier et al. 2017; Yoshida et al. 2018; García-Sánchez et al. 2018). In these studies, providing fully developed turbulence as inflow boundary conditions for the LES model is required, since

Corresponding author: Gwang-Jin Lee, gwangjin@yonsei.ac.kr
ABL turbulence plays a major role in the interaction with the building-generated turbulence. Typically, recycling techniques are used to provide such developed turbulence (e.g., Lund et al. 1998; Mayor et al. 2002; Kataoka and Mizuno 2002). However, long buffer zones in front of the target area are required to generate fully developed turbulence in LES with noncyclic lateral boundaries (e.g., Park et al. 2015; Gronemeier et al. 2017), therefore increasing the computational cost.

Alternatively, synthetic turbulence generators can be used (e.g., Xie and Castro 2008). This type of methods requires a priori knowledge of turbulence-related coefficients such as length and time scales and Reynolds stress tensor, among others. These parameters are often 
not available from observations or mesoscale models used to force the target LES-scale urban simulations, therefore making its application to real atmospheric conditions difficult. Finally, a precursor LES domain with cyclic lateral boundary conditions can be used to spin up turbulence (e.g., Lundquist et al. 2012), but this approach considerably increases the computational burden by requiring either concurrent or precomputed simulation of an additional LES domain. Moreover, all of these techniques have difficulties in handling time-varying wind direction conditions, which is another drawback when realistic meteorology is considered as large-scale forcing conditions to drive a building-resolving LES.

Muñoz-Esparza et al. (2014) recently proposed an alternative method that is based upon the use of stochastic perturbations of the potential temperature field on a region near the inflow boundaries of the LES domain, the so-called cell perturbation method. These finite-amplitude perturbations trigger the onset of threedimensional turbulence structures through local buoyancy effects, therefore resulting in an accelerated transition to fully developed turbulence within a reduced fetch. Optimal settings of the cell perturbation method were identified by Muñoz-Esparza et al. (2015) and MuñozEsparza and Kosović (2018), and its ability to produce realistic turbulence has been demonstrated in a variety of cases including a diurnal cycle in full-physics atmospheric simulations (Muñoz-Esparza et al. 2017) and semi-idealized scenarios dealing with ocean-island interactions and cloud formation (Jähn et al. 2016) and sea breeze over an urbanlike coast (Jiang et al. 2017).

Herein, we extend the previous works on the cell perturbation method to building-scale LES considering a real urban layout corresponding to the Seoul, South Korea, city area. Also, we quantify the implications of not using an inflow turbulence generator, as it is sometimes assumed that the complexity of the urban layout ensures by itself proper turbulence generation (e.g., Lundquist and Chan 2007; Letzel et al. 2008; Chen et al. 2015). The reminder of the paper is organized as follows. In section 2 the model description and simulation setup are introduced. Section 3 includes comparison between the observations and the simulated results at $3 \mathrm{~m}$ above ground level, and comparison between cell perturbation and nonperturbed inflow LES for turbulence quantities at higher heights is presented in section 4. Finally, the conclusions are presented in section 5 .

\section{Model description and simulation setup}

The parallelized large-eddy simulation model (PALM), which is a modern meteorological model (Maronga et al. 2015), is used to simulate building-resolving turbulent flow over the Seoul city area at 1440 LST 25 October 2013. The LES model solves the nonhydrostatic incompressible Navier-Stokes equations under the Boussinesq approximation. The advection terms in the governing equations are discretized in space using finite-difference equidistant horizontal grid spacings and stretchable vertical grid spacings on Arakawa staggered C grid (Harlow and Welch 1965; Arakawa and Lamb 1977). And the advection terms in the governing equations are discretized using an upwind-biased fifth-order differencing scheme of Wicker and Skamarock (Wicker and Skamarock 2002) in combination with a third-order Runge-Kutta time-stepping scheme after Williamson (1980). The subgrid-scale (SGS) terms are parameterized using a linear eddy viscosity model, corresponding to the modified version of Moeng and Wyngaard (1988) and Saiki et al. (2000) after Deardorff (1980).

A local district of Seoul, a megacity in South Korea is selected in this study (Fig. 1). High-rise buildings with over 10 floors are densely distributed in this area. The average building height is $20.55 \mathrm{~m}$, and the height of the tallest building is $222.16 \mathrm{~m}$ above ground level. The airborne light detection and ranging (lidar) data scanned in 2009 with a density of approximately 25 points per square meter by the South Korea National Geographic Information Institute (NGII) are used to create a coarser-gridded elevation map with a 5-m resolution (Yi et al. 2012). There is a 4-yr time difference between the scanned date and simulation target time (2013). The elevation map is projected to the transverse Mercator projection (Korean 2000/Central Belt) and is used as bottom topography in the LESs. Additionally, buildings are removed from the topography and only smooth orography remains within a distance of three computational grid cells from the lateral boundaries (Figs. 1c,d) since the upwind advection scheme can cause abnormal values at near uneven bottom topography touching lateral boundaries. The mean height and maximum height of the elevation map are $h_{\text {mean }}=39.05 \mathrm{~m}$ and $h_{\text {max }}=239.84 \mathrm{~m}$, respectively. Rectangular grids are used, and the grid size in the $x$ and $y$ directions is $\Delta x=\Delta y=5 \mathrm{~m}$ with a horizontal domain extension of $3200 \mathrm{~m} \times 3200 \mathrm{~m}$. The grid size in the vertical direction is uniform with $\Delta z=$ $1.5 \mathrm{~m}$ up to $z=250 \mathrm{~m}\left(>h_{\max }\right)$ and then increases with an expansion ratio of 1.08 up to $z=359.41 \mathrm{~m}$. From this height up to the domain top height $(z=1174.41 \mathrm{~m})$, a uniform vertical grid of $\Delta z=10 \mathrm{~m}$ is used.

Quasi-steady approach is used to impose meteorological forcing on lateral boundaries of the LES model, where large-scale forcing is constant in time and resolved turbulence provides the flow with an unsteady behavior. Vertical profiles of horizontal velocity and potential temperature are obtained from a radiosonde 
(a)

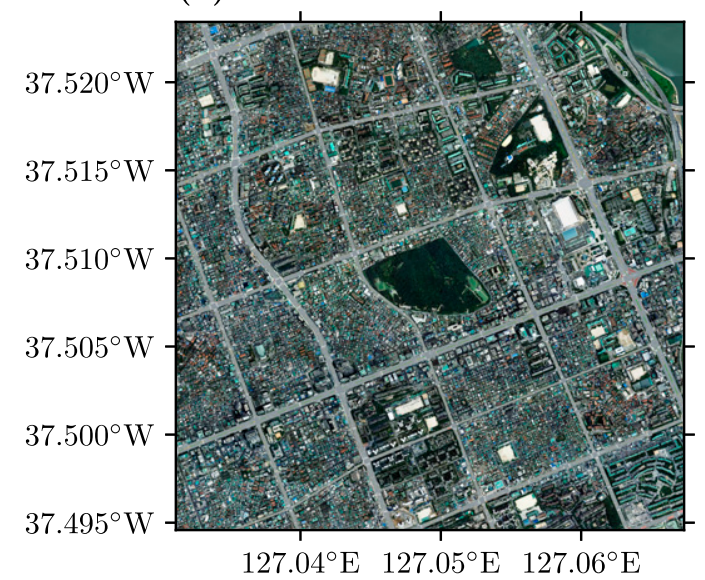

$127.04^{\circ} \mathrm{E} \quad 127.05^{\circ} \mathrm{E} \quad 127.06^{\circ} \mathrm{E}$

(c)

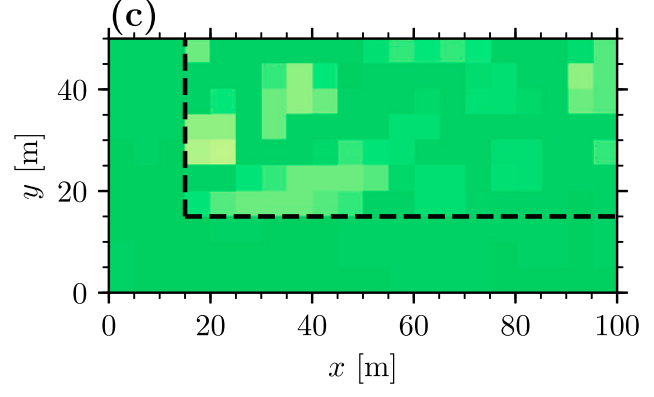

(b)

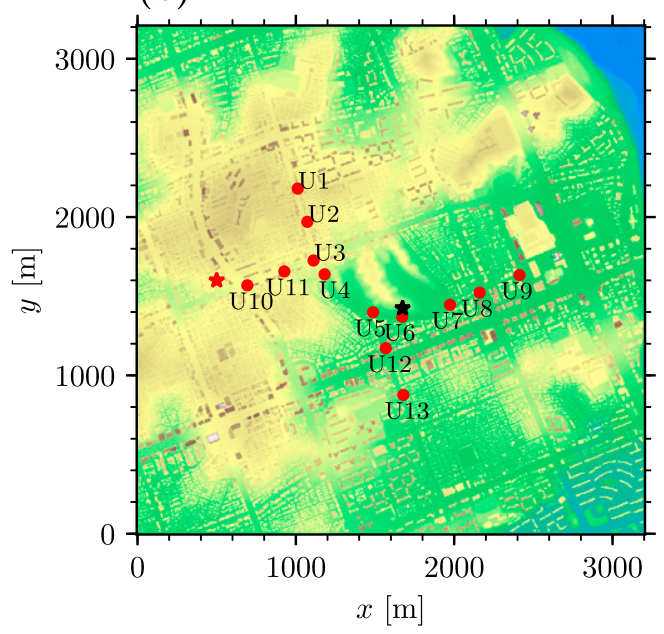

(d)

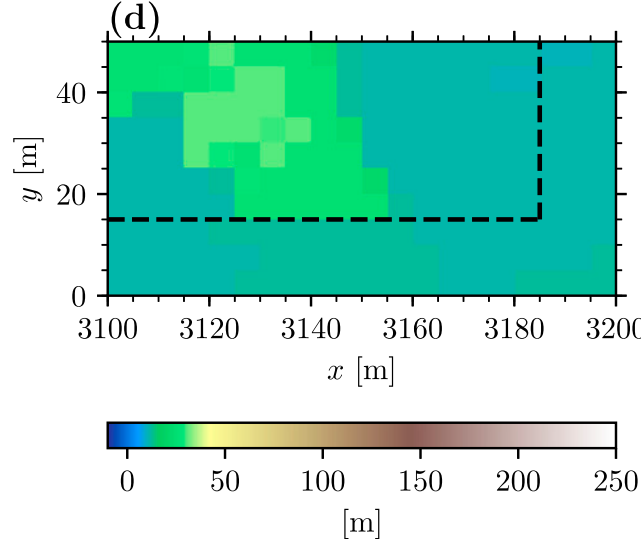

FIG. 1. (a) Aerial image of the selected local district of Seoul, South Korea. The copyright for the aerial image is held by the South Korea Ministry of Land, Infrastructure, and Transport (MOLIT). (b)-(d) Ground elevation and building-top surfaces in the computational domain. The 13 weather transmitters (U1-U13) are indicated by red circles and the departure point of radiosonde and the positions of vertical lines for releasing passive scalar tracer are indicated by black and red stars, respectively, in (b). Dashed lines in (c) and (d) represent boundaries of buildingremoving zone.

observation at 1439-1445 LST 25 October 2013 on a sunny day. The radiosonde took off from black star in Fig. 1b at 1439 LST and it arrived at the base of the inversion layer $\left(z_{i}=1010 \mathrm{~m}\right)$ at $1442 \mathrm{LST}$. Simplified profiles for inflow conditions are derived from the radiosonde data approximating to the neutrally stratified flow, although observations display the signature of convective instability in the lowest part of the ABL (Fig. 2a). The profile of potential temperature is set to a constant value of $286.1 \mathrm{~K}$ up to the base of the inversion layer, linearly increasing with the vertical gradient given by the best linear fit to the observation data in the inversion layer $\left(0.024 \mathrm{~K} \mathrm{~m}^{-1}\right)$. The direction of inflow is linearly interpolated to the observational directions and linearly extrapolated near the ground. The wind speed in the boundary layer is derived using the logarithmic wind profile as follows:

$$
u(z)=\frac{u_{*}}{\kappa} \ln \left(\frac{z-d}{z_{0}}\right) .
$$

Here, $u_{*}$ is the friction velocity, $\kappa$ is the von Kármán constant $(=0.41), z_{0}$ is the surface roughness length $(=0.1 \mathrm{~m})$, and $d$ is zero-plane displacement, which is approximated as $3 h_{\text {mean }} / 4$ (=29.28 m) (Holmes 2015). For the wind profile to match the velocity $U_{i}$ at the base of the inversion layer $z_{i}, u_{*}$ is calculated by $\kappa U_{i} / \ln \left[\left(z_{i}-d\right) / z_{0}\right]=0.281 \mathrm{~m} \mathrm{~s}^{-1}$. The wind speed above $z_{i}$ is set to be constant. The simplified profiles for inflow are imposed on all lateral boundaries and are fixed for simulation time. No buffer region is added. A Dirichlet boundary condition is applied at the top boundary and the Monin-Obukhov similarity theory is applied at the first grid from the bottom 


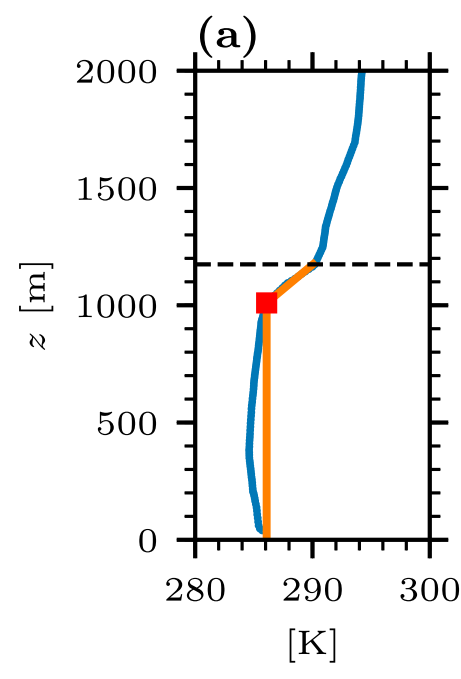

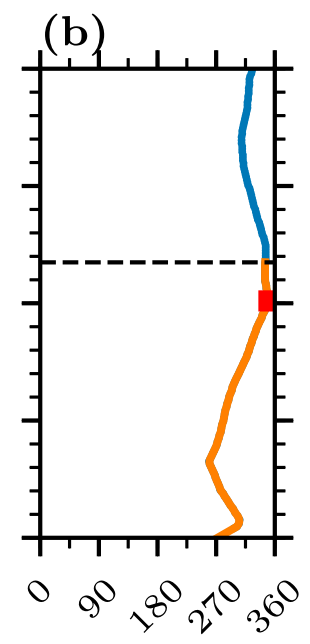

$\left[{ }^{\circ}\right]$

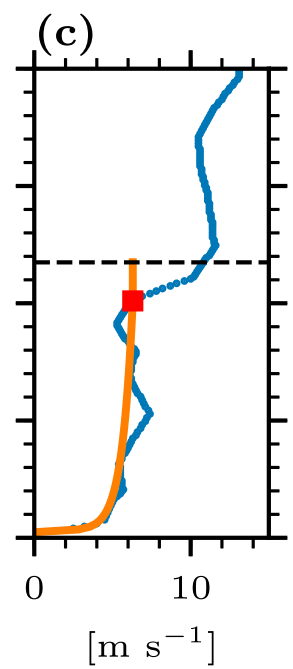

- observed simplified

FIG. 2. The observed vertical profiles from the radiosonde that departed from the point indicated by a black star in Fig. 1b at 1439-1445 LST 25 Oct 2013 and simplified profiles for lateral boundary conditions of LES model (a) potential temperature, (b) wind direction, and (c) wind speed. Red squares represent the corresponding values at the base of the inversion layer $z_{i}$, and dashed lines represent the domain-top height. The observational data are provided by the South Korea National Institute of Meteorological Sciences (NIMS).

boundary and horizontal/vertical walls of buildings. The Coriolis force is applied with the geographical latitude of $37.51^{\circ}$, corresponding to the selected region. No radiation, surface energy balance, or vegetation canopy effects are considered.

To generate inflow turbulence in our LES model, we use the cell perturbation method (Muñoz-Esparza et al. 2014; Muñoz-Esparza et al. 2015). The method is based upon the use of stochastic potential temperature perturbations uniformly distributed in the interval $\left[-\theta_{\text {pert }}\right.$, $\left.\theta_{\text {pert }}\right]$, applied over a region that covers three cells parallel to each lateral boundary. The cells are square bidimensional and have $8 \times 8$ grid points in the horizontal plane (one gridpoint extension in the vertical direction). The motivation for choosing eight grid points is that the fifth-order advection scheme used in the LES model dissipates energy rapidly for wavenumbers $k \geq 2 \pi / 6 \Delta x$ (Skamarock 2004). In this study, the cell perturbations are only applied along the western and northern boundaries of the LES domain (Fig. 3a) because the inflow directions are almost northwesterly (Fig. 2b). Potential temperature perturbations are introduced at each vertical grid from topography up to $z=19 z_{i} / 20$ (Fig. 3c). According to Muñoz-Esparza et al. (2015), the maximum perturbation amplitude $\theta_{\text {pert }}$ satisfying the optimum perturbation Eckert number $E_{c}=U_{g}^{2} /\left(c_{p} \theta_{\text {pert }}\right)=0.2$ is used, where $U_{g}$ is the geostrophic wind speed and $c_{p}$ is the specific heat capacity at constant pressure $\left(=1004 \mathrm{~J} \mathrm{~kg}^{-1} \mathrm{~K}^{-1}\right)$. In this study the geostrophic wind is set to the wind speed at $z_{i}, U_{g}=6.299 \mathrm{~m} \mathrm{~s}^{-1}$, and therefore the optimal $\theta_{\text {pert }}$ is $0.1976 \mathrm{~K}$. The perturbation time $t_{p}$ is set to satisfy the perturbation time scale $\Gamma=t_{p} U_{1} / d_{c}=1$, where $U_{1}\left(3.05 \mathrm{~m} \mathrm{~s}^{-1}\right.$ in this study) is the velocity magnitude of Eq. (1) at the mean height of topography and $d_{c}$ is the diagonal of the cell, to allow for the perturbations to be convected out of the cell before the flow to be perturbed again. As a result, an optimal $t_{p}$ of $18.55 \mathrm{~s}$ is obtained, which dictates the frequency with which new cell perturbations are repetitively imposed in the flow field. Figures $3 b$ and $3 d$ show the instantaneous potential temperature at final time $t=2800 \mathrm{~s}$, demonstrating how the cell perturbations imposed near the inflow boundaries quickly transition to developed turbulence features.

To compare between simulations with the cell perturbation method (so-called cell-perturbed LES) and without it, nonperturbed LES is also run in the exact same conditions except for not using the cell perturbation method. Both simulations required approximately $1000 \mathrm{~s}$ of spin-up time to reach a quasi-equilibrium state where the resolved-scale turbulent kinetic energy (TKE) averaged over the whole domain $\langle\tilde{e}\rangle$ is stabilized (Fig. 4). The tilde indicates a filtered quantity of LES, the angle bracket indicates the spatial (volume or horizontal) average, and the overbar indicates the temporal mean. It is worth 
(a)
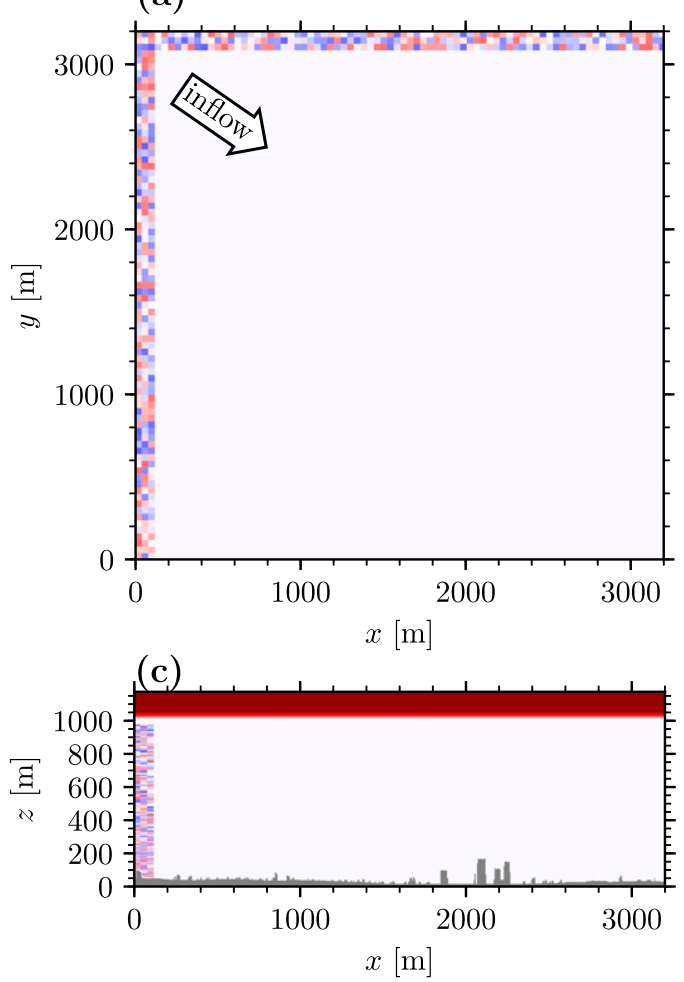

(b)
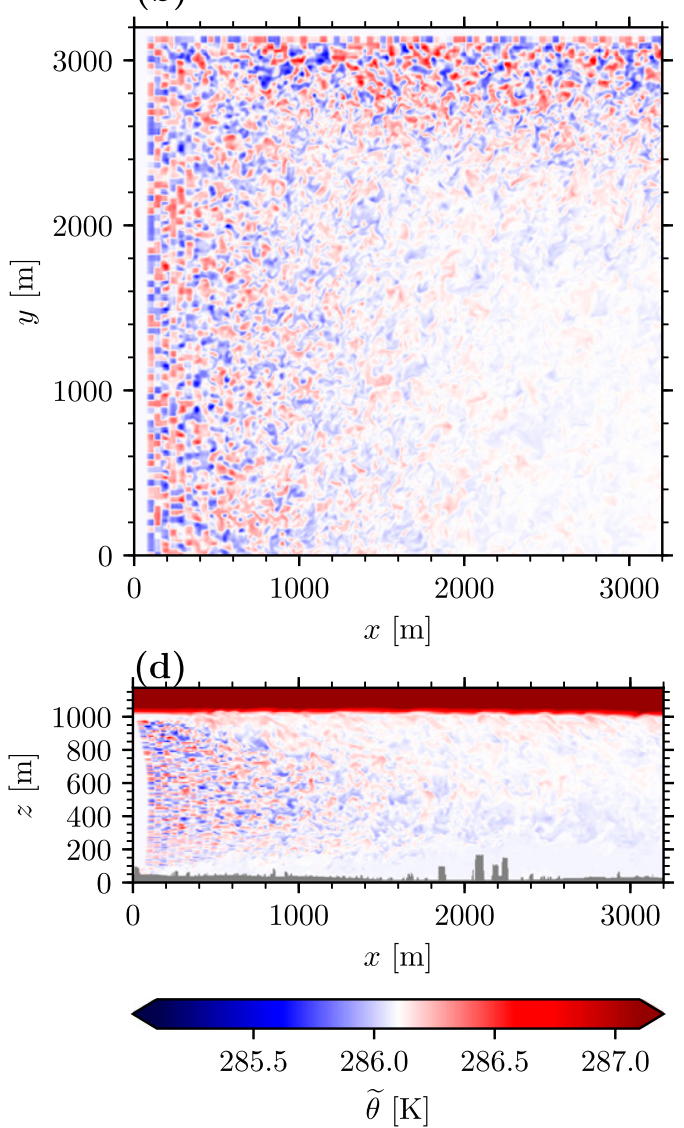

FIG. 3. Instantaneous potential temperature $\tilde{\theta}$ of the simulation with the cell perturbation method at $t=($ left $) 0$ and (right) $2800 \mathrm{~s}$ on a (a),(b) horizontal plane at $z=700 \mathrm{~m}$ and (c),(d) vertical plane at $y=1250 \mathrm{~m}$. Topography is shown in gray in (c) and (d).

remarking that despite reaching an equilibrium state, the nonperturbed LES consistently underestimates the magnitude of resolved velocity fluctuations even at domain-integrated scale. LES model data are therefore averaged for $1000-2800 \mathrm{~s}(=30 \mathrm{~min})$ to evaluate the mean properties, with an output frequency of $0.1 \mathrm{~s}$ used to derive turbulence statistics.

\section{Comparison between observations and LES for wind speed and direction}

To validate the LES results, 13 Vaisala weather transmitters WXT520 (labeled U1-U13) located in the target area were employed (Fig. 1b). These stations recorded 1-min-averaged horizontal wind speed and direction at a height of $3 \mathrm{~m}$ above the surface every minute. The accuracy of the wind speed and direction measurements are $\pm 0.3 \mathrm{~m} \mathrm{~s}^{-1}$ and $\pm 1^{\circ}$, respectively (Kim et al. 2016). The observation data within \pm 5 min of 1439 LST 25 October 2013 are $10 \mathrm{~min}$ averaged, and simulation results, $1000-2800 \mathrm{~s}$, are 30-min averaged.
Comparison of simulated mean horizontal wind speed (nonperturbed LES and cell-perturbed LES) with observations using a scatter diagram is presented in Fig. 5. In comparison with simulated wind speed with observed wind speed (Fig. 5a), five stations (U3, U5, U8, U9, and U13) display underestimations of simulated results.

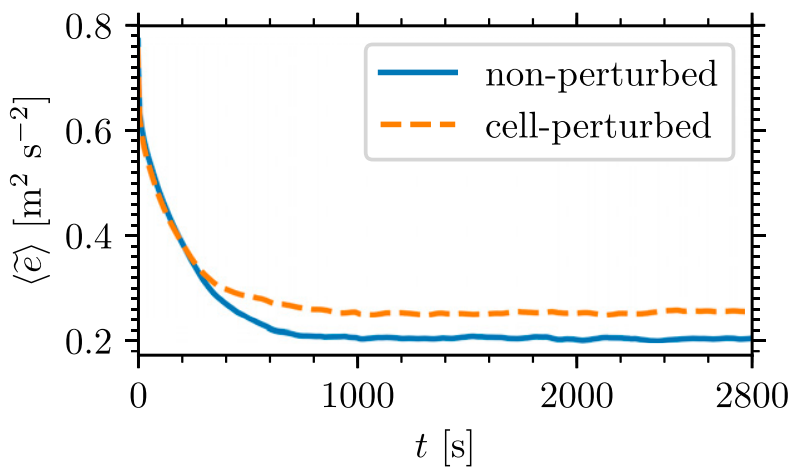

FIG. 4. Temporal evolution of the resolved-scale TKE averaged over the entire computational domain $\langle\tilde{e}\rangle$. 
(a)

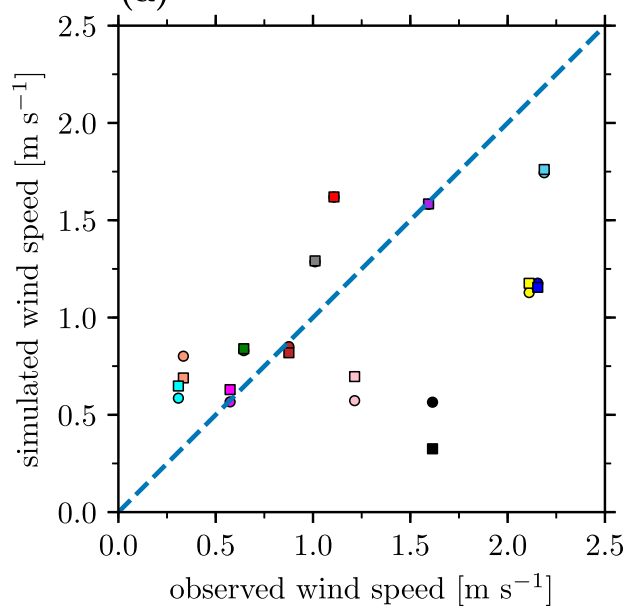

(b)

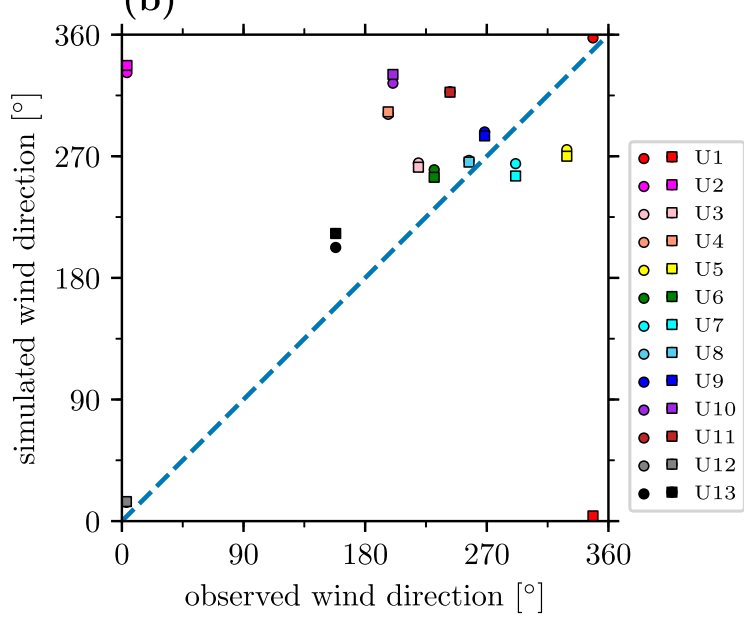

FIG. 5. Scatter diagrams between observed data and simulated data for (a) mean wind speed and (b) mean wind direction at 13 observation stations (Fig. 1b) at $3 \mathrm{~m}$ above ground level within $\pm 5 \mathrm{~min}$ of 1439 LST 25 Oct 2013. Circles represent the nonperturbed LES, and squares represent the cell-perturbed LES. The observational data are provided by the South Korea NIMS.

The reason for the underestimations is the absence of heat flux at the surface in our simulations. According to Gronemeier et al. (2017), when positive surface heat flux is applied to simulation, higher mean wind speed near the surface is simulated by downward vertical transport of momentum from upper levels. The reason for remarkable differences at U13 is that the shape of a building at the leeward side of U13 is distorted by $5-\mathrm{m}$ rasterization. The simulated results at five stations (U1, U4, U6, U7, and U12) show overestimation for wind speed. We attribute part of this to the lack of plant canopies (e.g., trees) around the stations in our simulations, which can produce relevant local drag effects influencing the station. Overall, mean inflow conditions were based on a one-dimensional profile derived from vertical measurements, which neglects nonturbulent spatial variability that may have been present. A recent study by García-Sánchez et al. (2017) using an uncertainty quantification analysis based on steady Reynolds-averaged Navier-Stokes (RANS) simulations has shown that the accuracy in wind speed and wind direction predictions is mainly controlled by uncertainty in the prescribed inflow wind direction (wind speed and roughness length are less influential). In spite of our simplified choice for inflow (e.g., use of only one vertical sounding), reasonable results were obtained for the majority of the stations. We speculate that LES is likely less susceptible to uncertainty in the inflow wind direction because of the unsteady nature of the resolved turbulence structures, which partially accounts for some directional variability in the resulting flow fields.
Comparison between simulations with and without the cell perturbation reveals relatively small differences regarding wind speed (Fig. 5a) and wind direction (Fig. 5b). This is in part due to the fact that observations are taken at $3 \mathrm{~m}$ above ground level, and that turbulence generated near the surface via frictional effects and the presence of the buildings overall results in the onset of turbulence even in the nonperturbed simulation. Nevertheless, there are certain locations U3 and U13 where the cell perturbations reduce or increase the wind speed bias to the measurement, respectively, and where the relative differences between the two simulations are approximately of $18 \%$ at $\mathrm{U} 3$ and $42 \%$ at U13.

To further quantify the impact of the presence of inflow turbulence on wind speed simulation at $3 \mathrm{~m}$ above ground level, statistical criteria including the index of agreement (IOA), root-mean-square error (RMSE), normalized-mean-square error (NMSE), fractional bias (FB), geometric mean bias (MG), geometric variance $(\mathrm{VG})$, and fraction of simulated data within a factor of 2 of observations (FAC2) are calculated. They are defined as

$$
\begin{aligned}
\mathrm{IOA} & =1-\frac{\frac{1}{n} \sum_{i=1}^{n}\left(S_{i}-O_{i}\right)^{2}}{\frac{1}{n} \sum_{i=1}^{n}\left(\left|O_{i}-\frac{1}{n} \sum_{j=1}^{n} O_{j}+\right| S_{i}-\left.\frac{1}{n} \sum_{j=1}^{n} O_{j}\right|^{2}\right)}, \\
\mathrm{RMSE} & =\sqrt{\frac{1}{n} \sum_{i=1}^{n}\left(S_{i}-O_{i}\right)^{2}},
\end{aligned}
$$




$$
\begin{aligned}
\mathrm{NMSE} & =\frac{\frac{1}{n} \sum_{i=1}^{n}\left(O_{i}-S_{i}\right)^{2}}{\left(\frac{1}{n} \sum_{i=1}^{n} O_{i}\right)\left(\frac{1}{n} \sum_{i=1}^{n} S_{i}\right)}, \\
\mathrm{FB} & =\frac{\frac{1}{n} \sum_{i=1}^{n} O_{i}-\frac{1}{n} \sum_{i=1}^{n} S_{i}}{0.5\left(\frac{1}{n} \sum_{i=1}^{n} O_{i}+\frac{1}{n} \sum_{i=1}^{n} S_{i}\right)}, \\
\mathrm{MG} & =\exp \left(\frac{1}{n} \sum_{i=1}^{n} \ln O_{i}-\frac{1}{n} \sum_{i=1}^{n} \ln S_{i}\right), \\
\mathrm{VG} & =\exp \left[\frac{1}{n} \sum_{i=1}^{n}\left(\ln O_{i}-\ln S_{i}\right)^{2}\right],
\end{aligned}
$$

FAC2 $=$ fraction of data that satisfy $0.5 \leq \frac{S_{i}}{O_{i}} \leq 2.0$.

In the above equations, $S_{i}$ is the simulated data, $O_{i}$ is the observed data, and $n$ is the number of the data. Table 1 presents the statistical agreement between the simulated wind speed and the observations at 13 weather transmitters. It can be shown that overall accuracy of both simulations at the observation sites is also acceptable. Table 1 also presents the comparison of nonperturbed LES and cell-perturbed LES. The results show that the nonperturbed LES is not as good as cell-perturbed LES regarding all verification indicators although there are local positions (U2, U7, U9, U11, and U13) at which the nonperturbed LES is better than the cell-perturbed LES. The overall results indicate that the settings of the LES are reasonable and that the horizontal mean velocity of the nonperturbed LES is not substantially different from the one of cell-perturbed LES at the level of $3 \mathrm{~m}$ above the surface. However, it is expected that at higher heights, the lack of properly resolved turbulence will further degrade the performance of the simulation without inflow turbulence, as will be shown in the next sections.

\section{Comparison between cell perturbation and nonperturbed inflow LES for turbulence quantities}

To investigate the characteristics of the turbulent velocity fields from the LES, the $x-y$ plane of instantaneous horizontal wind speed $\sqrt{\tilde{u}^{2}+\tilde{v}^{2}}$ at $z=250 \mathrm{~m}$ after $t=2800 \mathrm{~s}$ is shown in Fig. 6 comparing nonperturbed LES with cell-perturbed LES. In Fig. 6a turbulence emerges at the leeward side of tall buildings, while smooth flow (i.e., less turbulent) appears where no tall buildings are
TABLE 1. Verification indicators for simulated wind speed at 13 observation stations (Fig. 1b) at $3 \mathrm{~m}$ above ground level within \pm 5 min of 1439 LST 25 Oct 2013 . The acceptance criteria of model performance are based on Hanna et al. (2004).

\begin{tabular}{lccc}
\hline \hline $\begin{array}{c}\text { Verification } \\
\text { index }\end{array}$ & $\begin{array}{c}\text { Nonperturbed } \\
\text { LES }\end{array}$ & $\begin{array}{c}\text { Cell-perturbed } \\
\text { LES }\end{array}$ & $\begin{array}{c}\text { Acceptance } \\
\text { criteria }\end{array}$ \\
\hline IOA & 0.68 & 0.67 & - \\
RMSE & 0.58 & 0.6 & - \\
NMSE & 0.27 & 0.29 & $<4$ \\
FB & 0.17 & 0.17 & $-0.3<\mathrm{FB}<0.3$ \\
MG & 0.93 & 0.91 & $0.7<\mathrm{MG}<1.3$ \\
VG & 1.35 & 1.47 & $<1.6$ \\
FAC2 & 0.77 & 0.77 & $>0.5$ \\
\hline
\end{tabular}

present in the upstream direction (e.g., at $\mathrm{P} 1, \mathrm{P} 2$, and P5). In contrast, Fig. 6b qualitatively shows that turbulence is generated not only at the leeward side of tall buildings but consistently all over the domain, including regions where there are no buildings to create shear instabilities in the flow field and therefore induce local turbulence production. Figure 7 shows instantaneous vertical velocity $\tilde{w}$ on a vertical cross section in the streamwise direction at $y=1250 \mathrm{~m}$ after $t=2800 \mathrm{~s}$ for nonperturbed LES and cell-perturbed LES. It is clear that in the LES case using the cell perturbation method the region ranging from the top of buildings to the base of the inversion layer $\left(z_{i}=1010 \mathrm{~m}\right)$ is more turbulent than in the nonperturbed LES, and develops eddy structures that bridge with the building-induced structures. It is worth noting that while the localized drag forcing imposed by the building structures instigates development of resolved turbulence features, such mechanical process remains constrained to the roughness sublayer in the urban ABL and occurs heterogeneously over the domain. However, these turbulent fluctuations propagate vertically at a slow rate, analogous to an internal boundary layer, which in this case is determined by the interface between turbulent and nonturbulent flow. Toward the end of the domain, $x=3200 \mathrm{~m}$, Fig. 7 a exhibits the height of the turbulent layer as approximately $300 \mathrm{~m}\left(<z_{i}\right)$ in the nonperturbed simulation, while the simulation using the cell perturbation method results in approximately $z_{i}$ (Fig. 7b), an underestimation of $\approx 70 \%$.

Further understanding into the characteristics and energy distribution of a turbulent flow can be achieved by examining energy spectra. Temporal energy spectra of vertical and horizontal velocity components is presented in Fig. 8 for $z=78.75,250$, and $700 \mathrm{~m}$, corresponding to the locations of the six black-dotted points presented in Fig. 6. Spectra are calculated over a 30-min time interval ( $t=1000-2800 \mathrm{~s})$, and are smoothed using subwindows of $50 \mathrm{~s}$ and $75 \%$ overlapping. Near the 
(a)

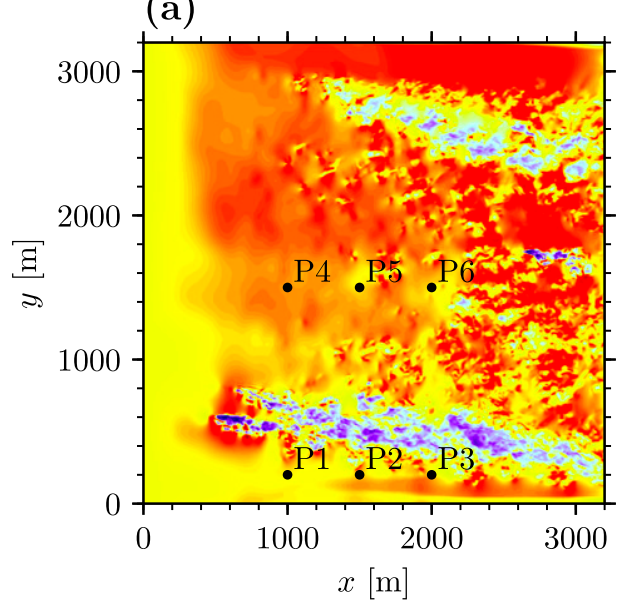

(b)

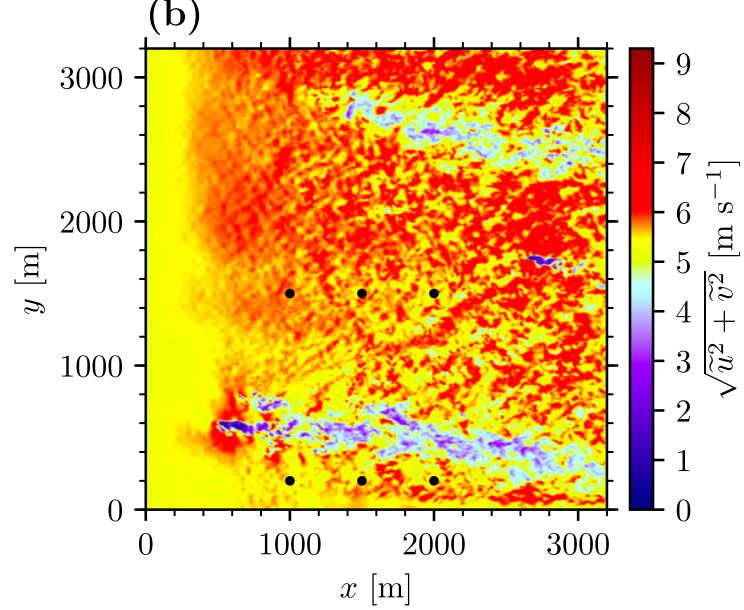

FIG. 6. Instantaneous horizontal wind speed $\sqrt{\tilde{u}^{2}+\tilde{v}^{2}}$ on a horizontal plane at $z=250 \mathrm{~m}$ after $t=2800 \mathrm{~s}$ of simulation for (a) the nonperturbed LES and (b) the cell-perturbed LES. Six locations labeled P1-P6 are indicated by black dots.

surface, $z=78.75 \mathrm{~m}$, the energy spectra from the unperturbed LES is similar to the ones from the cell-perturbed simulation. However, as height is increased, significant energy underestimation is found. At $z=250 \mathrm{~m}, \mathrm{P} 1, \mathrm{P} 2$, and $\mathrm{P} 4$ locations exhibit not only reduced energy levels but a stronger energy decrease as frequency is increased, with slopes lower than the expected $-2 / 3$ as observed in the cell-perturbed LES case. At this height, P3 and P6 locations result in better agreement, since lateral spread of wakes from surrounding upstream buildings help to instigate turbulence development. However, right above $z=250 \mathrm{~m}$, turbulence fluctuations start to vanish because of the lack of proper inflow conditions and consequent insufficient turbulent transport, resulting in dramatic energy underestimations at all scales (see bottom panels in Fig. 8).

As confirmed by the spectral analysis, the LES run without an inflow turbulence generation method relies on local urban features to initiate the turbulent energy production and cascade processes. This leads to a heterogeneous turbulence development pattern, which depends upon the specific urban layout and the incoming ABL properties (especially wind speed and direction). To demonstrate this feature, the relative difference of time-averaged resolved-scale TKE between the nonperturbed LES $\overline{\tilde{e}}_{\text {non-CP }}$ and the cell-perturbed LES $\overline{\tilde{e}}_{\mathrm{CP}}$ is presented in Fig. 9:

$$
\overline{\tilde{e}}_{\text {diff }}=100 \frac{\overline{\tilde{e}}_{\mathrm{CP}}-\overline{\tilde{e}}_{\text {non-CP }}}{\overline{\tilde{e}}_{\mathrm{CP}}} .
$$

Spatial distribution of relative resolved-scale TKE difference on a vertical cross section at $y=1452.5 \mathrm{~m}$ from
Fig. 9a shows that nonperturbed LES presents essentially turbulence void from $z \approx 250 \mathrm{~m}$ to $z_{i}$. As with the vertical velocity contours presented in Fig. 7, the development of a building-influenced sublayer is observed in Fig. 9a, which separates the turbulent region near the building structures and the nonturbulent flow aloft that occupies the rest of the ABL (similar results are found at all $y$ locations). Within the urban canopy layer, the relative differences of $30 \%-50 \%$ are found with alternating sign (Fig. 9b). This is due to the fact that the positive or negative relative difference of the mean turbulent momentum fluxes with height occurs in the urban canopy layer in comparison between simulations with and without turbulent inflow (Gronemeier et al. 2015),

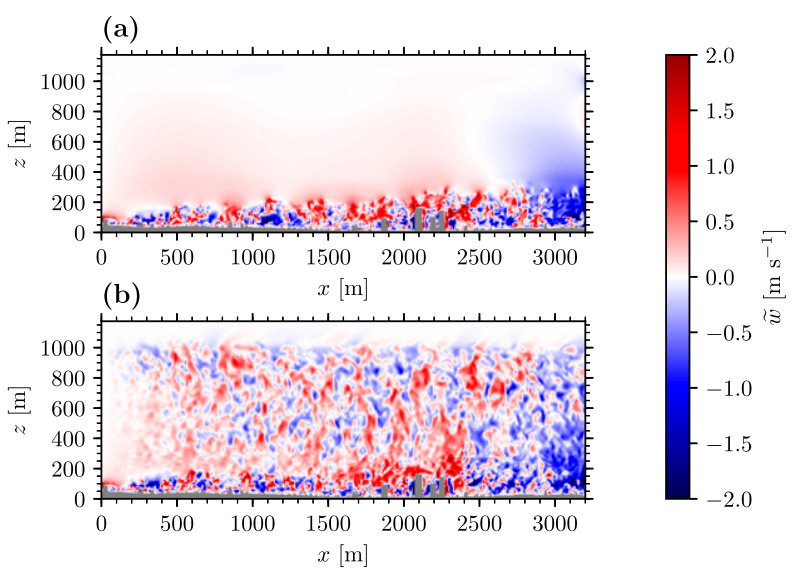

FIG. 7. Instantaneous vertical velocity component $\tilde{w}$ on a vertical plane at $y=1252.5 \mathrm{~m}$ after $t=2800 \mathrm{~s}$ of simulation for (a) the nonperturbed LES and (b) the cell-perturbed LES. Topography is shown in gray. 

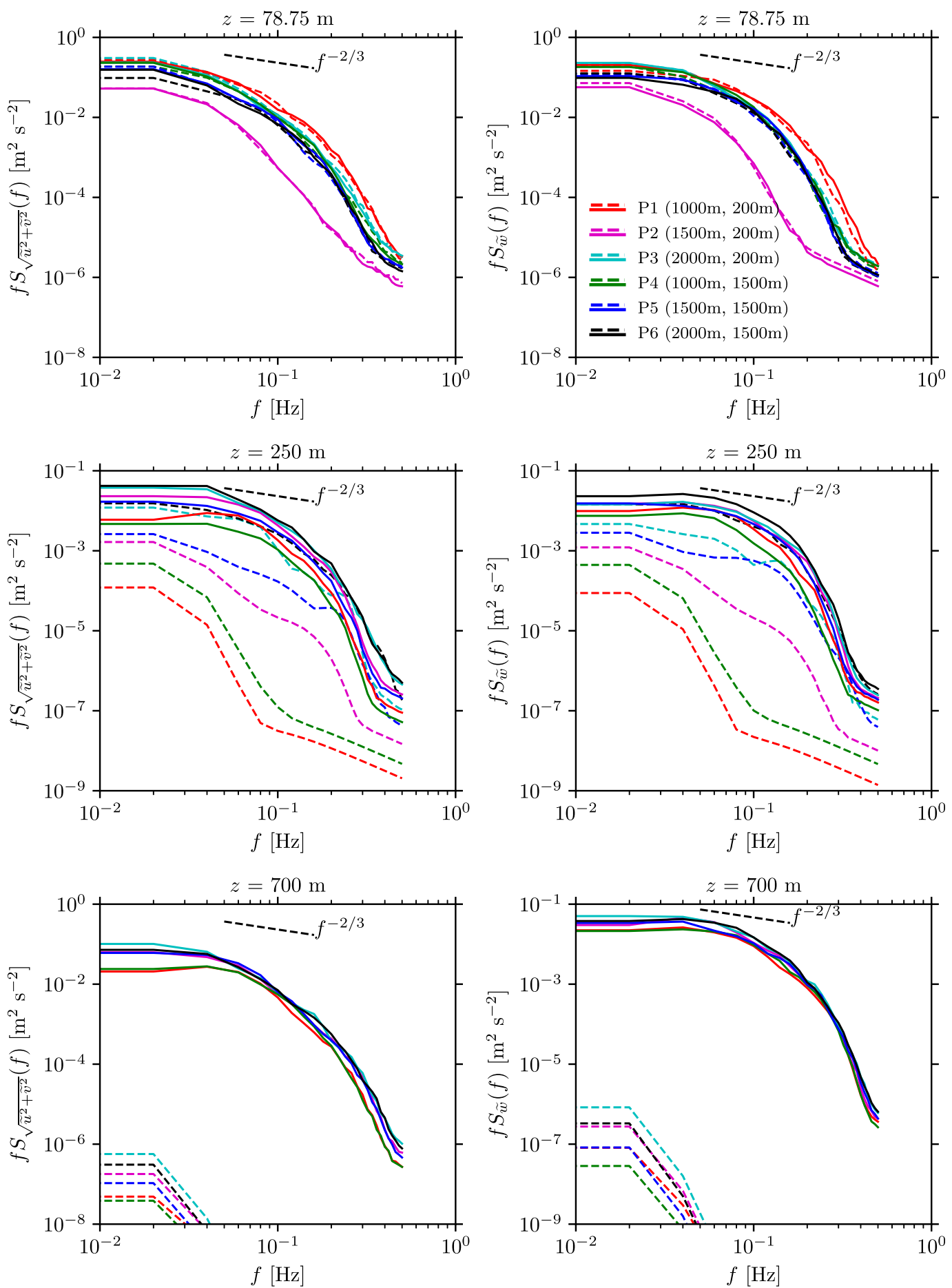

FIG. 8. The frequency spectra $f S(f)$ of (left) horizontal wind speed $\sqrt{\tilde{u}^{2}+\tilde{v}^{2}}$ and (right) vertical velocity $\tilde{w}$ as a function of frequency $f$ at the selected six locations P1-P6 in Fig. 6 for $1000 \leq t \leq 2800 \mathrm{~s}$ with the heights of $z=$ (top) 78.75, (middle) 250, and (bottom) $700 \mathrm{~m}$. Lines indicate the nonperturbed LES (dashed) and the cell-perturbed LES (solid).

resulting in the resolved-scale TKE differences. This implies that the simulation without turbulent inflow yields both excess and deficit of the mean resolved-scale TKE in the urban canopy layer. Not even at the near-surface layer and for large fetches, proper turbulence is ensured in the unperturbed LES case at all locations (Fig. 9c). Examples of that are zoomed in over the $x-z$ plane in Fig. 9b and $x-y$ plane at $z=78.75 \mathrm{~m}$ from Fig. 9d. 
(a)
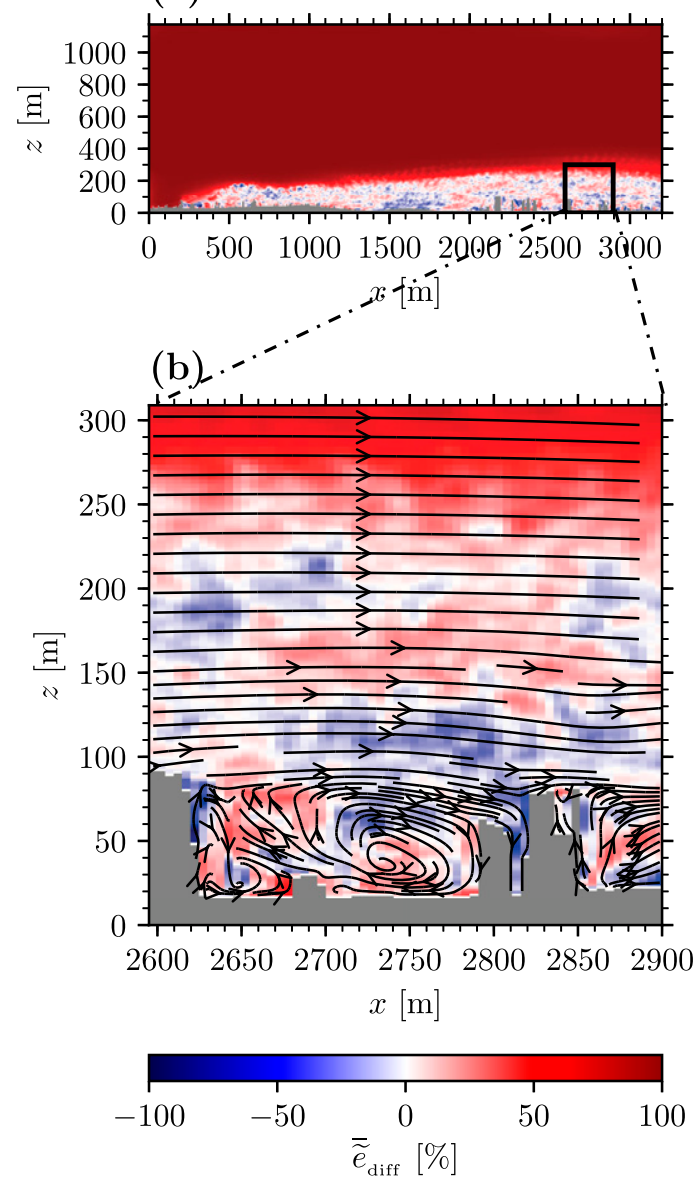

(c)

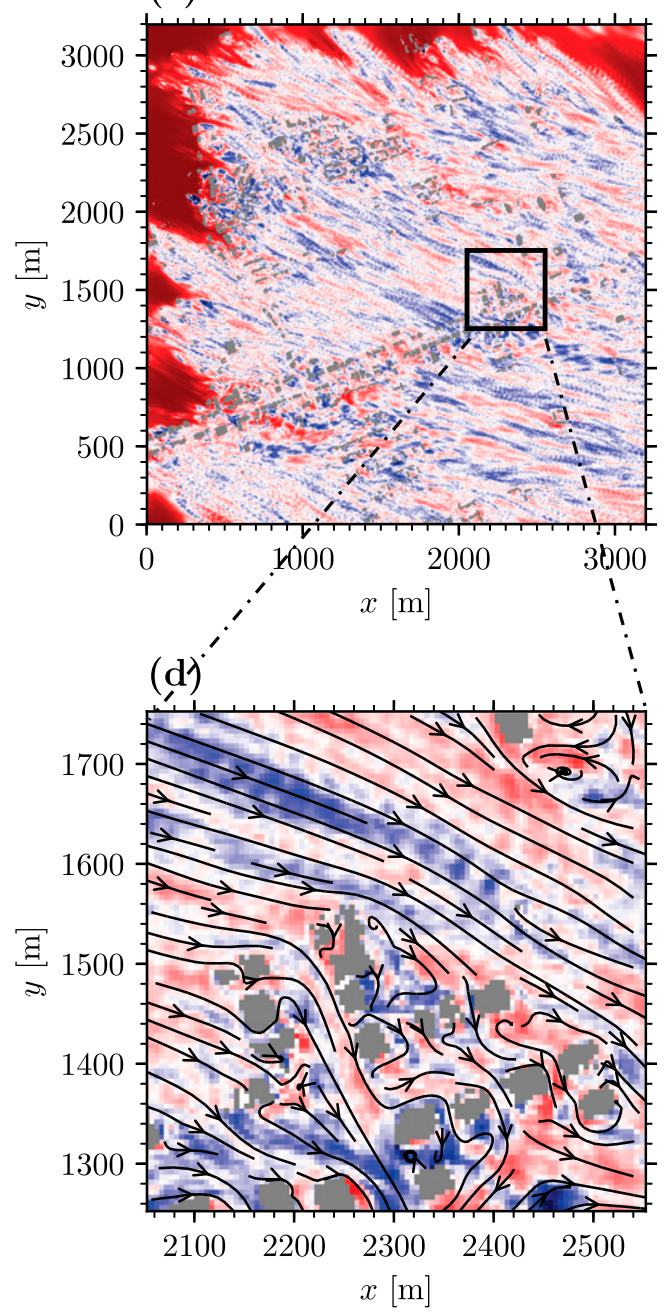

FIG. 9. The relative difference of time-averaged (1000-2800 s) resolved-scale TKE between the nonperturbed and cell-perturbed LESs on (a),(b) an $x-z$ plane of $y=1452.5 \mathrm{~m}$ and (c),(d) an $x-y$ plane of $z=$ $78.75 \mathrm{~m}$. The streamline of the mean velocity of the cell-perturbed LES is overlaid in (b) and (d). Topography is shown in gray.

Regions with significant resolved-scale TKE excess and deficit often emerge in complex recirculating flow regions, as indicated by the streamlines from the cell perturbation run. In these regions, turbulence levels are very important since they dictate the extent of the recirculating areas as well as velocity deficit and its recovery in the lee side of buildings and building clusters, in turn impacting the velocity field.

Another important feature characterizing a turbulent $\mathrm{ABL}$ is the momentum flux or turbulent correlations. The instantaneous vertical turbulent momentum flux $u^{\prime} w^{\prime}$ can be classified into four quadrants: outward interaction $\left(u_{+}^{\prime} w_{+}^{\prime}\right)$, ejection $\left(u_{-}^{\prime} w_{+}^{\prime}\right)$, inward interaction $\left(u_{-}^{\prime} w_{-}^{\prime}\right)$, and sweep $\left(u_{+}^{\prime} w_{-}^{\prime}\right)$ (Raupach and Thom 1981), owing to the nature of the associated turbulent structures responsible for the turbulent transfer. Figure 10 shows the joint probability density function (PDF) of $u^{\prime}$ and $w^{\prime}$ over the entire domain at different heights. Here $u^{\prime}$ and $w^{\prime}$ denote deviations from the time-averaged (mean) streamwise velocity $\overline{\tilde{u}}$ and vertical velocity $\overline{\tilde{w}}$, respectively. The joint PDF of $u^{\prime}$ and $w^{\prime}$ is defined as

$$
\begin{aligned}
f_{u^{\prime} w^{\prime}}= & P\left[u_{i}^{\prime}-\Delta u^{\prime}<u^{\prime} \leq u_{i}^{\prime}+\Delta u^{\prime}, w_{j}^{\prime}\right. \\
& \left.-\Delta w^{\prime}<w^{\prime} \leq w_{j}^{\prime}+\Delta w^{\prime}\right] .
\end{aligned}
$$

Each turbulent velocity fluctuation over the whole domain was discretized in 50 bins, using a uniform bin spacing to calculate the joint PDF, $\Delta u^{\prime}=\Delta w^{\prime}=0.1 \mathrm{~m} \mathrm{~s}^{-1}$. The results at $z=250 \mathrm{~m}$ show that momentum transport is mostly controlled by sweeps and ejections emerging 

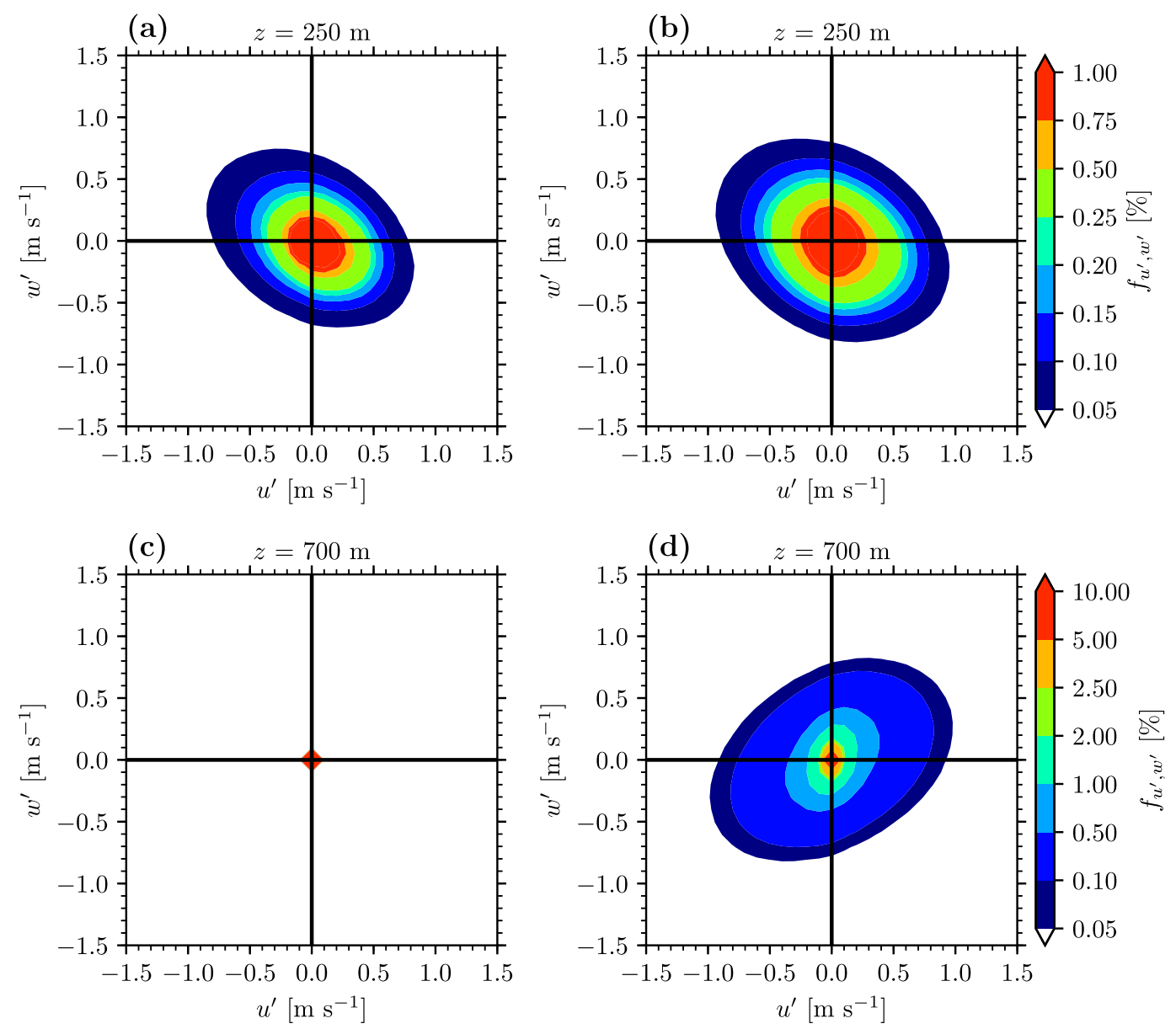

FIG. 10. Fields of the joint probability density function of $u^{\prime}$ and $w^{\prime}$ for $1000 \leq t \leq 2800 \mathrm{~s}$ on a horizontal plane of $z=$ (a),(b) 250 and (c),(d) $700 \mathrm{~m}$ in the whole domain for (left) the nonperturbed LES and (right) the cellperturbed LES.

under the presence of a rough surface (Figs. 10a,b). The unperturbed simulation exhibits slightly less frequent outward and inward interaction, while the probability of sweeps and ejections is similar. Overall, the joint PDF is not significantly different from them at that height. At $z=700 \mathrm{~m}$, the turbulent fluctuations $u^{\prime}$ and $w^{\prime}$ in the nonperturbed LES are essentially zero, evidencing the lack of resolved turbulence at these heights (cf. Figs. 10c and 10d). Moreover, significantly less frequent outward interactions, ejections, inward interactions, and sweeps events occurred in the unperturbed LES.

A relevant aspect and application of LES in urban environments is to study transport and dispersion of pollutants (e.g., Lundquist and Chan 2007; Lundquist et al. 2012). To quantify the impact of not employing a turbulence inflow technique on pollutant dispersion, a passive scalar tracer distributed over a vertical line was released at a specific location $(x=500 \mathrm{~m}, y=1600 \mathrm{~m})$ from topography up to $z_{i}$, and with source release uniform in space and constant in time of $s=1.0 \mathrm{~kg} \mathrm{~m}^{-3}$. Figs. 11a and $11 \mathrm{~b}$ show volume-rendered threedimensional scalar concentration for the unperturbed and the cell-perturbed LES cases at $t=2800 \mathrm{~s}$. This qualitative comparison shows that for $z<200 \mathrm{~m}$ where the presence of the buildings contributes to spin up turbulence development, scalar dispersion patterns are similar. However, at higher heights $(300<z<1000 \mathrm{~m})$, the scalar source is mainly advected downstream with very reduced spatial dispersion (Fig. 11c), essentially following the vertically varying wind direction imposed as lateral boundary conditions. In contrast, the cellperturbed simulation exhibits the presence of eddy structures that efficiently mix the passive scalar source with the surroundings (Fig. 11d).

Turbulent scalar transport can be investigated by examining turbulent fluxes. For that purpose, the turbulent scalar fluctuation $s^{\prime}$ is defined as deviation from the timeaveraged (mean) scalar concentration $\overline{\tilde{s}}$, consistent with 

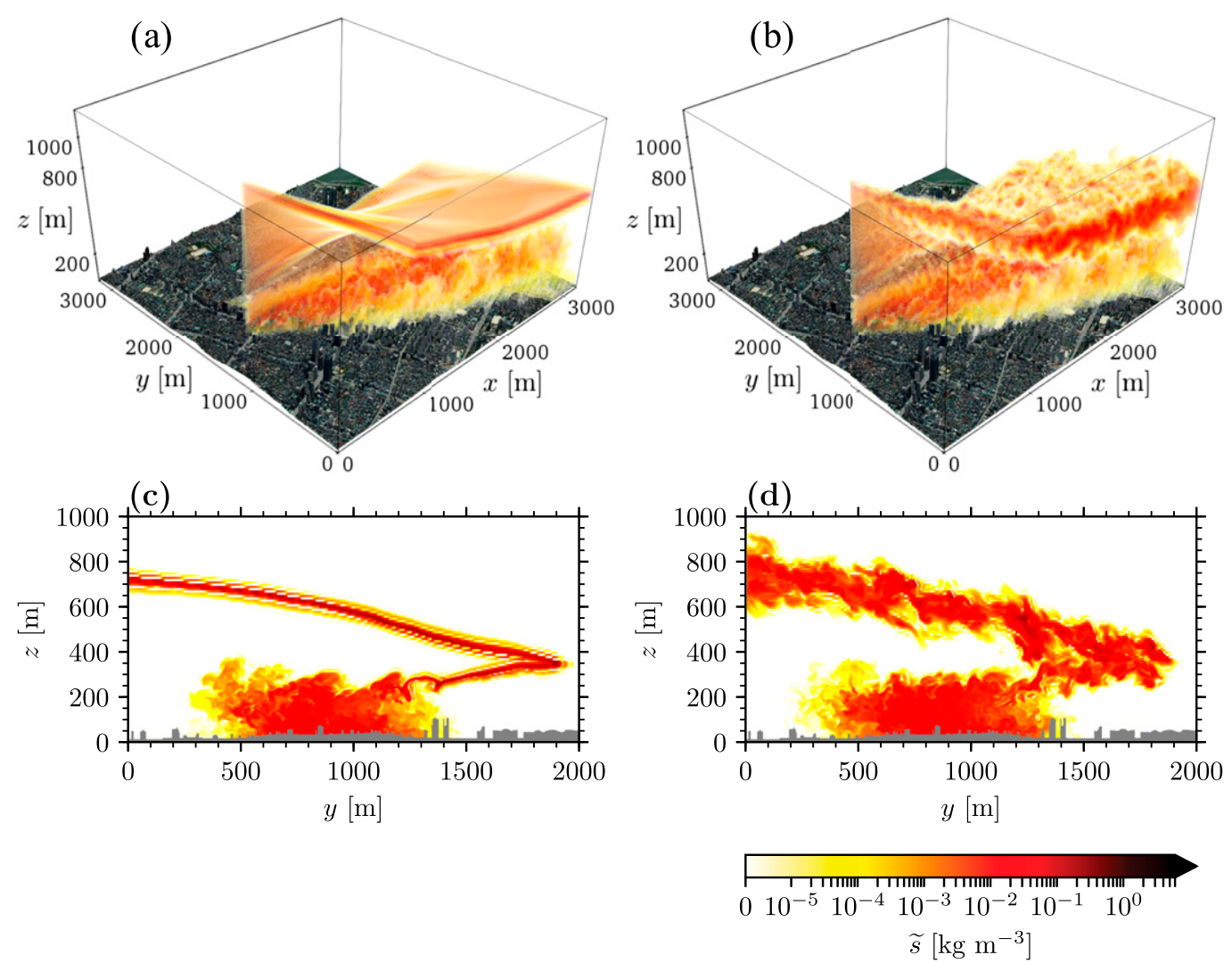

FIG. 11. Instantaneous field of scalar concentration $\tilde{s}$ for (left) the nonperturbed LES and (right) the cell-perturbed LES after $t=2800 \mathrm{~s}$ of simulation. (a),(b) Volume-rendered three-dimensional scalar concentration. The model domain is vertically stretched by a factor of 1.5 just for better visualization. The copyrights for the underlying aerial image and building objects are held by the South Korea MOLIT. (c),(d) Cross sections on a vertical $y-z$ plane at $x=2502.5 \mathrm{~m}$, with topography shown in gray.

the definitions used for turbulent velocity fluctuations. Instantaneous spatial distribution of the magnitude of vertical scalar flux $\left|w^{\prime} s^{\prime}\right|$ is presented in Fig. 12. In agreement with the previous analysis, $\left|w^{\prime} s^{\prime}\right|$ at $z=78.75 \mathrm{~m}$ displays a similar pattern in both the unperturbed and the cell-perturbed LES runs, with turbulent scalar flux developing into a wakelike distribution because of near-surface mixing. In contrast, $\left|w^{\prime} s^{\prime}\right|$ at $z=250 \mathrm{~m}$ already starts to exhibit signature of a deficient turbulent distribution. This can be observed from the more homogeneous and of less magnitude scalar flux, especially evident for $500<x<2000 \mathrm{~m}$. This effect becomes more dramatic with increasing height, an example of which are Figs. 12e and $12 \mathrm{f}$ at $z=700 \mathrm{~m}$, and where the only contribution to the flux is arising from large wavelengths, which are generally much weaker than the cell perturbation results and lack of a proper eddy distribution.

Quantification of the scalar flux differences $\left\langle\left|w^{\prime} s^{\prime}\right|\right\rangle_{\text {diff }}$ and $\left\langle\left|\sqrt{u^{\prime 2}+v^{\prime 2}} s^{\prime}\right|\right\rangle_{\text {diff }}$ defined as Eq. (9) is included in Fig. 13, both for the vertical and horizontal counterparts, through vertical profiles of horizontally averaged flux. The horizontal average is taken over the region where either the nonperturbed LES or the cell-perturbed LES had nonzero scalar fluxes. For $z<150 \mathrm{~m}$, the unperturbed and the cell-perturbed cases are nearly identical. The underestimation of scalar flux rapidly grows to almost $100 \%$ at $z \approx 400 \mathrm{~m}$, and remains at these levels for the rest of the ABL.

\section{Conclusions}

Urban flow in the densely built-up area of Seoul was simulated with high-resolution LES $(\Delta=5 \mathrm{~m})$, imposing initial and boundary condition based upon radiosonde profiles. Comparison of the LES results with observations located at $3 \mathrm{~m}$ above ground showed a reasonable agreement for near-surface wind speed and direction. Then, the impact of the presence of inflow turbulence on the turbulence structure and characteristics of the ABL was thoroughly analyzed. For inflow turbulence generation, we extended the use of the cell 

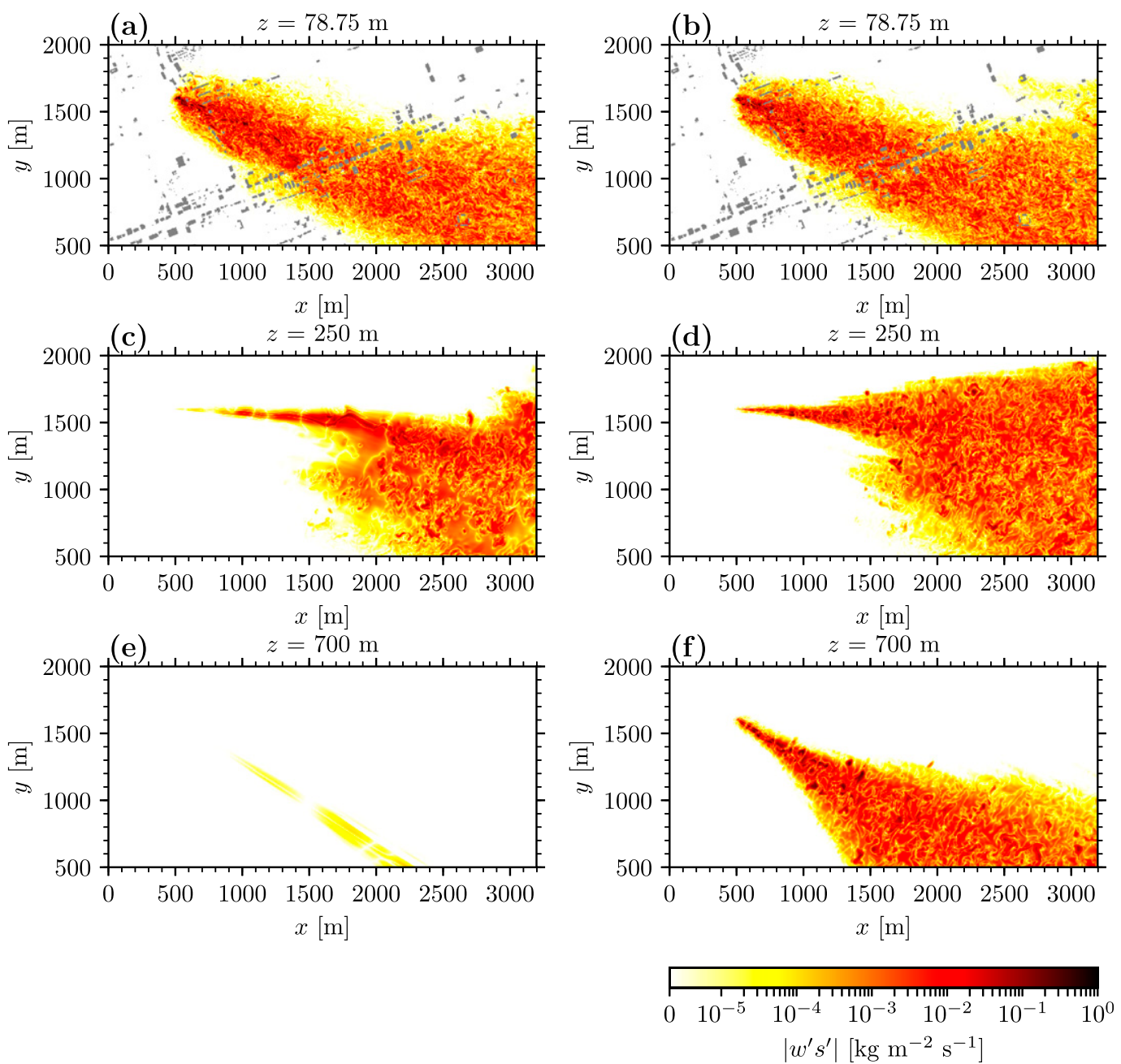

FIG. 12. Absolute vertical turbulent scalar concentration flux at $t=2800 \mathrm{~s}$ on a horizontal planes at $z=$ (a),(b) 78.75, (c),(d) 250, and (e),(f) $700 \mathrm{~m}$ for (left) the nonperturbed LES and (right) the cell-perturbed LES. Topography is shown in gray.

perturbation method, compared to a simulation where no inflow turbulence was applied.

We found that buildings act as an efficient source of turbulence production through shear instabilities created by the heterogeneous drag pattern originated within the urban canopy layer. However, turbulence development only occurs within the vertical extent of the building layout in the simulation without inflow turbulence, yielding formation of an internal boundary layer that interfaces between turbulence developed in the urban canopy and nonturbulent flow aloft. Moreover, the turbulence development level within the internal boundary layer strongly depends on the local upstream building layout, exhibiting areas of significant resolved-scale TKE excess and deficit emerging in complex recirculating flow regions in turn affecting velocity and its recovery in the lee side of buildings and building clusters.
In-depth analysis of turbulence quantities revealed that for $z \geq 250 \mathrm{~m}\left(\approx 6.4 h_{\text {mean }}\right.$ and $\approx 1.04 h_{\text {max }}$, where $h_{\text {mean }}$ and $h_{\text {max }}$ are the mean and maximum heights of the elevation map used in the simulations, respectively), turbulence fluctuations start to rapidly vanish because of insufficient turbulent transport that arises from the lack of proper inflow conditions. This in turn results in dramatic energy underestimations at all of the resolvable turbulence scales, as shown in the energy spectra of velocity components. Deficient turbulent mixing was also found to underestimate the strength of the joint PDF of momentum flux. Quantification of passive tracer transport and dispersion revealed that underestimation of the spatial averaged scalar fluxes in the unperturbed case grows to almost $100 \%$ from $z=350 \mathrm{~m}$ to $z \approx z_{i}$, evidencing the large potential impacts on pollutant transport studies. 
(a)

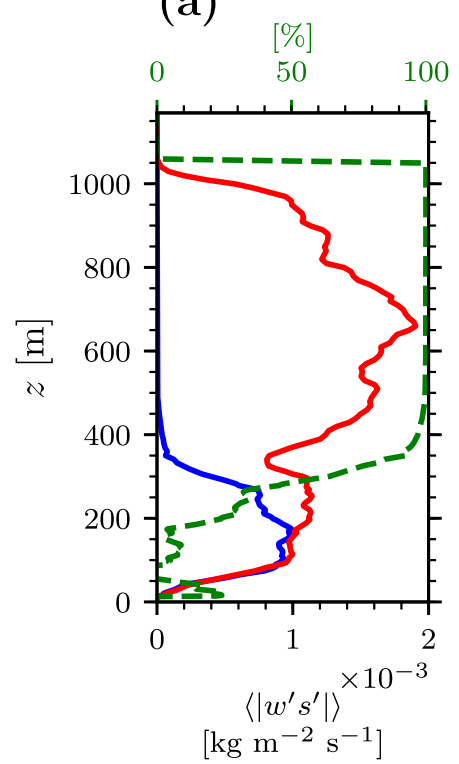

(b)

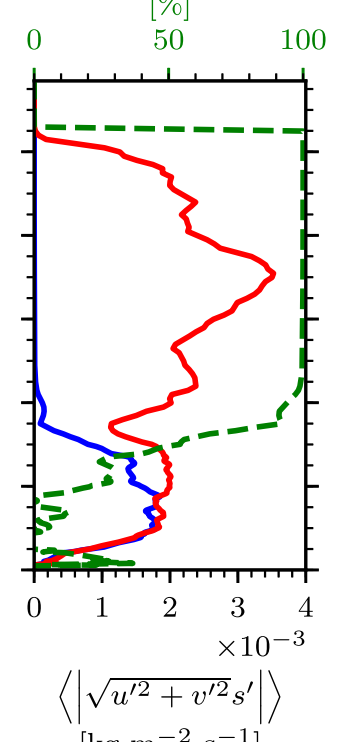

$\left[\mathrm{kg} \mathrm{m} \mathrm{m}^{-2} \mathrm{~s}^{-1}\right]$

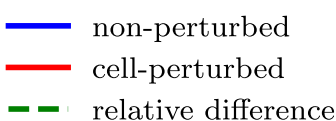

FIG. 13. Vertical profiles of (a) vertical turbulent scalar concentration flux magnitude and (b) horizontal turbulent scalar concentration flux magnitude horizontally averaged over the region where nonzero scalar fluxes are present (valid at $t=2800 \mathrm{~s}$ ). The relative difference of scalar concentration fluxes (green dashed lines) is defined in a similar way to Eq. (9).

A neutrally stratified ABL was considered in this study, despite the fact that in the real atmosphere stability effects are often present. While it could seem a priori intuitive to expect convective instability to always result in a very fast turbulence development, MuñozEsparza and Kosović (2018) have recently shown that it is the ratio of horizontal advection to the convective velocity scale that determines the required fetch for turbulence to develop from unperturbed later boundary conditions in convective ABLs. Therefore, only when the convective velocity scale is dominant (vertical transport is more significant) that the turbulencedevelopment fetch becomes significantly reduced. Nevertheless, we recommend the use of inflow turbulence technique irrespective of atmospheric stability to ensure more reliable LES computations, especially when considering heterogeneous time-evolving atmospheric forcing conditions.

Herein, we have shown that resolved urban features are not sufficient to guarantee proper and homogeneous turbulence development in LES of urban flows, in turn strongly affecting turbulence processes within the urban ABL. These findings demonstrate the need for LES practitioners to incorporate inflow generation methods in their urban-scale simulations. To that end, the feasibility of the cell perturbation method to generate forcing-consistent ABL inflow turbulence in building-resolving LES has been demonstrated. In addition, we expect similar conclusions to be applicable for simulations of atmospheric flows over complex terrain, where terrain features are often presumed to instigate appropriate turbulence development.

Acknowledgments. This work was supported by the National Research Foundation of Korea (NRF) (Grant 2015R1A5A1009350) and the Korea Meteorological Administration Research and Development Program under Grant KMI (KMI2018-01410). We would like to acknowledge high-performance computing support from Cheyenne (https://doi.org/10.5065/D6RX99HX) provided by NCAR's Computational and Information Systems Laboratory, sponsored by the National Science Foundation. Two-dimensional figures have been produced using the python libraries Matplotlib (Hunter 2007). Volumerendered three-dimensional fields were generated using ParaView (Ayachit 2015). We thank S. Raasch, M. Sühring and T. Gronemeier for helpful discussions about PALM through a ticketing system (https:// palm.muk.uni-hannover.de/trac/wiki/tickets). And we also thank H. Yang for discussions about simulation setup and validation, and $\mathrm{S}$. Weon for giving a technical tip for three-dimensional visualization. We appreciate three anonymous reviewers for providing valuable comments that helped improving the clarity of the manuscript.

\section{REFERENCES}

Arakawa, A., and V. R. Lamb, 1977: Computational design of the basic dynamical processes of the UCLA general circulation model. Methods in Computational Physics, J. Chang, Ed., Vol. 17, Elsevier, 173-265, https://doi.org/10.1016/B978-0-12460817-7.50009-4.

Ayachit, U., 2015: The ParaView Guide: A Parallel Visualization Application. Kitware, Inc., 276 pp.

Chen, G., X. Zhu, W. Sha, T. Iwasaki, H. Seko, K. Saito, H. Iwai, and S. Ishii, 2015: Toward improved forecasts of sea-breeze horizontal convective rolls at super high resolutions. Part I: Configuration and verification of a Down-Scaling Simulation System (DS ${ }^{3}$ ). Mon. Wea. Rev., 143, 1849-1872, https://doi.org/10.1175/ MWR-D-14-00212.1.

Deardorff, J. W., 1980: Stratocumulus-capped mixed layers derived from a three-dimensional model. Bound.-Layer Meteor., 18, 495-527, https://doi.org/10.1007/BF00119502.

García-Sánchez, C., G. Van Tendeloo, and C. Gorlé, 2017: Quantifying inflow uncertainties in RANS simulations of urban pollutant dispersion. Atmos. Environ., 161, 263-273, https:// doi.org/10.1016/j.atmosenv.2017.04.019.

_ J. van Beeck, and C. Gorlé, 2018: Predictive large eddy simulations for urban flows: Challenges and opportunities. Build. Environ., 139, 146-156, https://doi.org/10.1016/j.buildenv.2018.05.007. 
Gronemeier, T., A. Inagaki, M. Gryschka, and M. Kanda, 2015: Large-eddy simulation of an urban canopy using a synthetic turbulence inflow generation method. J. Japan Soc. Civil Eng., 71B, 43-48, https://doi.org/10.2208/jscejhe.71.I_43.

_- S. Raasch, and E. Ng, 2017: Effects of unstable stratification on ventilation in Hong Kong. Atmosphere, 8, 168, https://doi.org/10.3390/atmos8090168.

Hanna, S. R., O. R. Hansen, and S. Dharmavaram, 2004: FLACS CFD air quality model performance evaluation with Kit Fox, MUST, Prairie Grass, and EMU observations. Atmos. Environ., 38, 4675-4687, https://doi.org/10.1016/j.atmosenv.2004.05.041.

Harlow, F. H., and J. E. Welch, 1965: Numerical calculation of time dependent viscous incompressible flow of fluid with free surface. Phys. Fluids, 8, 2182-2189, https://doi.org/10.1063/ 1.1761178.

Holmes, J. D., 2015: Wind Loading of Structures. CRC press, 58 pp.

Hunter, J. D., 2007: Matplotlib: A 2D graphics environment. Comput. Sci. Eng., 9, 90-95, https://doi.org/10.1109/MCSE.2007.55.

Jähn, M., D. Muñoz-Esparza, F. Chouza Keil, O. Reitebuch, O. Knoth, M. Haarig, and A. Ansmann, 2016: Investigations of boundary layer structure, cloud characteristics and vertical mixing of aerosols at Barbados with large eddy simulations. Atmos. Chem. Phys., 16, 651-674, https:// doi.org/10.5194/acp-16-651-2016.

Jiang, P., Z. Wen, W. Sha, and G. Chen, 2017: Interaction between turbulent flow and sea-breeze front over urban-like coast in large-eddy simulation. J. Geophys. Res. Atmos., 122, 52985315, https://doi.org/10.1002/2016JD026247.

Kataoka, H., and M. Mizuno, 2002: Numerical flow computation around aeroelastic 3D square cylinder using inflow turbulence. Wind Struct., 5, 379-392, https://doi.org/10.12989/ was.2002.5.2_3_4.379.

Kim, G.-H., Y.-G. Lee, D.-G. Lee, and B.-J. Kim, 2016: Analyzing the cooling effect of urban green areas by using the multiple observation network in the Seonjeongneung region of Seoul, Korea. J. Environ. Sci. Int., 25, 1475-1484, https://doi.org/ 10.5322/JESI.2016.25.11.1475.

Letzel, M. O., M. Krane, and S. Raasch, 2008: High resolution urban large-eddy simulation studies from street canyon to neighbourhood scale. Atmos. Environ., 42, 8770-8784, https:// doi.org/10.1016/j.atmosenv.2008.08.001.

Lund, T. S., X. Wu, and K. D. Squires, 1998: Generation of turbulent inflow data for spatially-developing boundary layer simulations. J. Comput. Phys., 140, 233-258, https://doi.org/ 10.1006/jcph.1998.5882.

Lundquist, J. K., and S. T. Chan, 2007: Consequences of urban stability conditions for computational fluid dynamics simulations of urban dispersion. J. Appl. Meteor. Climatol., 46, 10801097, https://doi.org/10.1175/JAM2514.1.

Lundquist, K. A., F. K. Chow, and J. K. Lundquist, 2012: An immersed boundary method enabling large-eddy simulations of flow over complex terrain in the WRF model. Mon. Wea. Rev., 140, 3936-3955, https://doi.org/10.1175/MWR-D-11-00311.1.

Maronga, B., and Coauthors, 2015: The parallelized large-eddy simulation model (PALM) version 4.0 for atmospheric and oceanic flows: Model formulation, recent developments, and future perspectives. Geosci. Model Dev., 8, 2515-2551, https:// doi.org/10.5194/gmd-8-2515-2015.

Mayor, S. D., P. R. Spalart, and G. J. Tripoli, 2002: Application of a perturbation recycling method in the large-eddy simulation of a mesoscale convective internal boundary layer. J. Atmos. Sci., 59, 2385-2395, https://doi.org/10.1175/1520-0469(2002) 059<2385:AOAPRM>2.0.CO;2.
Moeng, C.-H., and J. C. Wyngaard, 1988: Spectral analysis of largeeddy simulations of the convective boundary layer. J. Atmos. Sci., 45, 3573-3587, https://doi.org/10.1175/1520-0469(1988) 045<3573:SAOLES $>2.0$. CO 2 .

Muñoz-Esparza, D., and B. Kosović, 2018: Generation of inflow turbulence in large-eddy simulations of non-neutral atmospheric boundary layers with the cell perturbation method. Mon. Wea. Rev., 146, 1889-1909, https://doi.org/10.1175/ MWR-D-18-0077.1.

- _ _ J. Mirocha, and J. van Beeck, 2014: Bridging the transition from mesoscale to microscale turbulence in numerical weather prediction models. Bound.-Layer Meteor., 153, 409440, https://doi.org/10.1007/s10546-014-9956-9.

_ - _- J. van Beeck, and J. Mirocha, 2015: A stochastic perturbation method to generate inflow turbulence in large-eddy simulation models: Application to neutrally stratified atmospheric boundary layers. Phys. Fluids, 27, 035102, https://doi.org/10.1063/1.4913572.

, J. K. Lundquist, J. A. Sauer, B. Kosović, and R. R. Linn, 2017: Coupled mesoscale-LES modeling of a diurnal cycle during the CWEX-13 field campaign: From weather to boundarylayer eddies. J. Adv. Model. Earth Syst., 9, 1572-1594, https:// doi.org/10.1002/2017MS000960.

Park, S.-B., J.-J. Baik, and S.-H. Lee, 2015: Impacts of mesoscale wind on turbulent flow and ventilation in a densely built-up urban area. J. Appl. Meteor. Climatol., 54, 811-824, https:// doi.org/10.1175/JAMC-D-14-0044.1.

Raupach, M., and A. S. Thom, 1981: Turbulence in and above plant canopies. Annu. Rev. Fluid Mech., 13, 97-129, https://doi.org/ 10.1146/annurev.fl.13.010181.000525.

Saiki, E. M., C.-H. Moeng, and P. P. Sullivan, 2000: Large-eddy simulation of the stably stratified planetary boundary layer. Bound.-Layer Meteor., 95, 1-30, https://doi.org/10.1023/A: 1002428223156.

Skamarock, W. C., 2004: Evaluating mesoscale NWP models using kinetic energy spectra. Mon. Wea. Rev., 132, 3019-3032, https://doi.org/10.1175/MWR2830.1.

Smolarkiewicz, P. K., R. Sharman, J. Weil, S. G. Perry, D. Heist, and G. Bowker, 2007: Building resolving large-eddy simulations and comparison with wind tunnel experiments. J. Comput. Phys., 227, 633-653, https://doi.org/10.1016/ j.jcp.2007.08.005.

Wicker, L. J., and W. C. Skamarock, 2002: Time-splitting methods for elastic models using forward time schemes. Mon. Wea. Rev., 130, 2088-2097, https://doi.org/10.1175/1520-0493(2002) $130<2088$ :TSMFEM $>2.0 . \mathrm{CO} ; 2$.

Williamson, J. H., 1980: Low-storage Runge-Kutta schemes. J. Comput. Phys., 35, 48-56, https://doi.org/10.1016/00219991(80)90033-9.

Xie, Z.-T., and I. P. Castro, 2008: Efficient generation of inflow conditions for large eddy simulation of street-scale flows. Flow Turbul. Combust., 81, 449-470, https://doi.org/10.1007/ s10494-008-9151-5.

Yi, C.-Y., S. M. An, K.-R. Kim, Y.-J. Choi, and D. Scherer, 2012: Improvement of air temperature analysis by precise spatial data on a local-scale-A case study of Eunpyeong New Town in Seoul. J. Korean Assoc. Geogr. Inf. Stud., 15, 144-158, https://doi.org/10.11108/kagis.2012.15.1.144.

Yoshida, T., T. Takemi, and M. Horiguchi, 2018: Large-eddysimulation study of the effects of building-height variability on turbulent flows over an actual urban area. Bound.-Layer Meteor., 168, 127-153, https://doi.org/10.1007/s10546-018-0344-8. 